\title{
It takes all sorts to make a world
}

Some observations about optimality by a layman, not for professional scholars

\author{
by Carlo Barghini
}

Chi dietro a iura e chi ad amforismi sen giva, e chi seguendo sacerdozio, e chi regnar per forza o per sofismi, e chi rubare e chi civil negozio, chi nel diletto de la carne involto s'affaticava e chi si dava a l'ozio, quando, da tutte queste cose sciolto, con Bëatrice m'era suso in cielo cotanto glorïosamente accolto.

\author{
One given to legal learning went his way, \\ one medicine, the priesthood one pursued, \\ and lordship one, by force or sophistry; \\ one practised theft, and public business one, \\ one, in the pleasures of the flesh involved, \\ was growing weary, one to idleness \\ and ease was giving up his life, while \\ I, from all these things set free, was up in Heaven \\ with Beatrice so gloriously received.
}

\begin{abstract}
Evolutionary biology is a historical science and there is no maths that can cope with history. In order to bypass this difficulty and make evolutionary biology a hard science, population geneticists, together with behavioral ecologists, have invented a new fake biology, whose main tool is optimization. I highlight the shortcomings that affect this concept.
\end{abstract}

I wonder what optimization could means if we are speaking about complex organisms. If you think on your own that it is just nonsense, you can skip reading this article. Otherwise it can be useful to continue. Nothing new, to be true, only things that any biologist knows; but behavioral ecologists as well as population geneticists think they are not so important.

There are two different obstacles preventing optimization of complex organisms. Firstly there are many different ways for complex organisms to stay alive in a complex environment and we may wonder what is the optimal one. Secondly optimal fitness can be achieved only for traits designed to fit environmental features which are fixed or can change in a predicable way; as randomness is widespread in complex environments, optimality of the individual overall may not be achieved. As Dante noted, everyone pulls a living as can. Only in heaven you can find perfection and optimality without constraints.

Just to begin with, it may be useful to briefly review the geometric model of adaptation, proposed by the great eugenicist Ronald Fisher in 1930 (Fisher 1930), which was the basis of the new synthesis: the micromutational model of the walk toward optimality. Just a hint, as the theme is well known.

Pick up a n-dimentional sphere centered in $\mathrm{O}$ with diameter $\mathrm{d}$ and $\mathrm{n}$ as large as you want. Consider a point $\mathrm{A}$ on the surface of this sphere that can make a move at random in any direction. The 
question is this: What is the probability that the point A will approach to the center of the sphere by means of a single random move $r$ ? That depends on the diameter $d$ of the sphere, on the number $n$ of its dimensions and on the magnitude $r$ of the translation. Obviously, for $r \geq d$ there is no chance whatever of approach. For $r<d$ probability depends on $d, n$ and $r$. If we assume $d / \sqrt{ } n$ as the unit of measure of $r$, chances are provided by this graph:

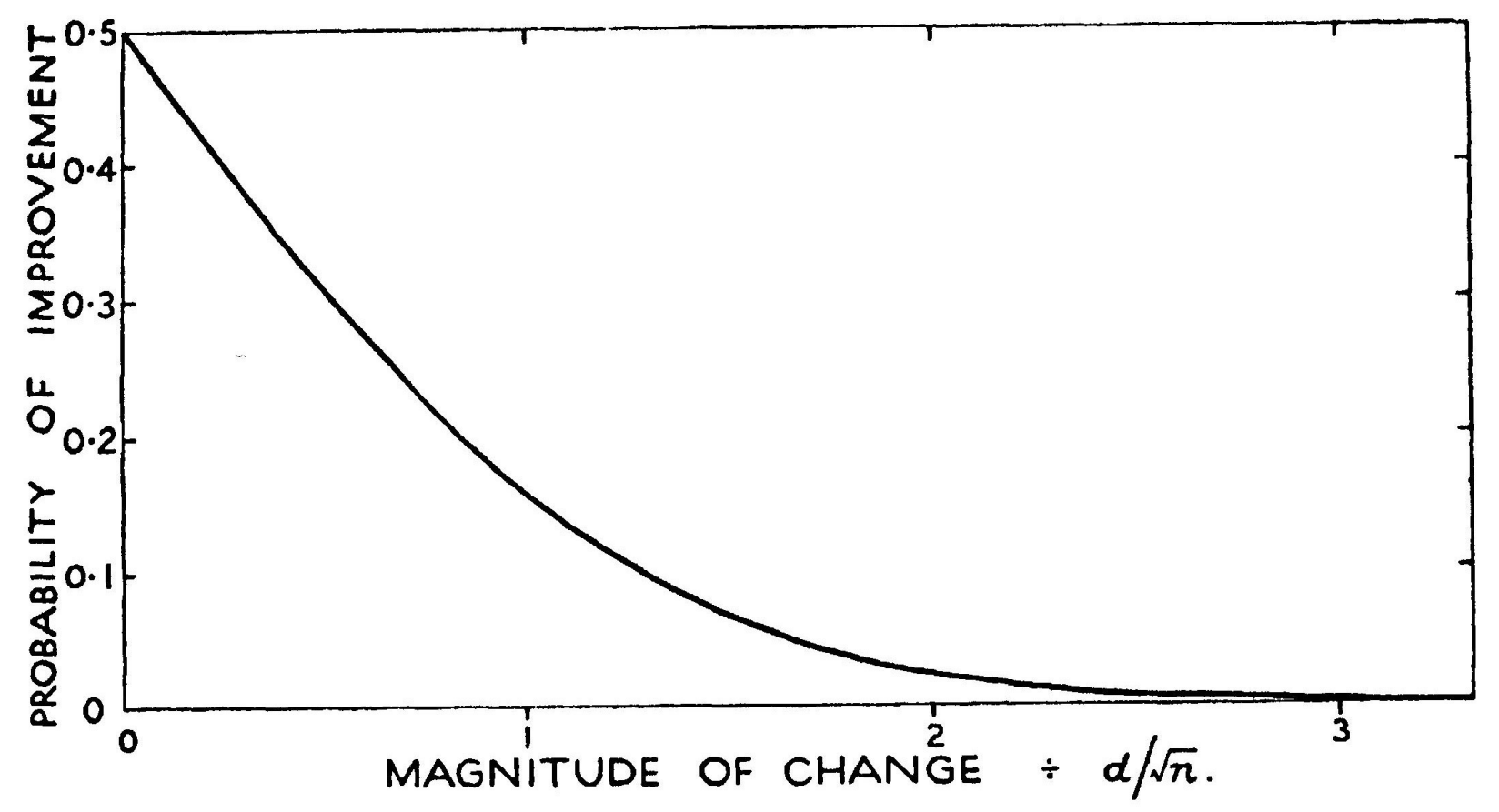

Figure 1

Now let's try to give this model a biological meaning. The center O means optimality. The point A means a population that has been moved away from optimality following a deterioration of the environment. The $\mathrm{n}$ axes measure the distance of any trait from optimality. Traits must be orthogonal (is not an easy job to choose traits that are really orthogonal) and are, we could say, weight, vision, gait.... and so on; but it is not really so, because these are not all orthogonal and anyone of these should be subdivided in many other minor traits, namely other dimensions. Don't ask how many traits have humans, although Orr (2000) has suggested how you can determine an organism's (just a microbe's) effective dimensionality through a thought experiment. Nor it is the case of asking if John von Neumann approached to optimality of more than Marilyn Monroe. Finally, random moves are mutations, or rather the infallible phenotypic effects of mutations: ontogeny doesn't matter. We can see that the probability of improvement of a single mutation approaches to $1 / 2$ when the magnitude of change approaches to zero, and decreases exponentially as the magnitude increases. It's important to note that $\mathrm{n}$ (the number of traits) matters a lot: as $\mathrm{n}$ 
increases, the magnitude of profitable translations decreases with its square root. This is what is named the cost of complexity. The conclusion of the story is that small mutations are more likely to be favorable and, furthermore, it's more difficult to improve humans than bacteria, since the latter have fewer traits than the former, which is a guess even a child could have had without any multidimensional sphere. Actually I don't understand why increasing of $\mathrm{n}$ should produce complexity. I wonder how many definitions of complexity go around among scholars (Mitchell 2009). Anyway size, namely the number of traits (if only you are able to count them), is really a poor measure for complexity. Nor it is a reliable measure of complexity the number of base pairs or the number of genes: actually Arabidopsis has about the same number of genes as humans do and the amoeba has about 223 times as many base pairs as humans do, but I don't think they are more complex than humans. Just reflect: if a genome, namely the bean bag of genes (Mayr, 1954), is composed of $\mathrm{n}$ genes, each corresponding to a single phenotypic trait and every trait performs only a single function, natural selection can optimize all of them, one by one, without stumbling on any complexity.

Well, everyone can choose the names he prefers as long as ambiguity does not arise. Since 'complexity' is mostly used to indicate the non-linearity that emerges as a result of interactions (say epistasis, pleiotropy, reaction norms), it will be better to give up using it to refer to size or to the amount of information. To be sure, information, although useful, is costly to be acquired and burdensome to be managed. But this is by no means complexity, this is simply the load of information, which arises as its amount increases. Let's call this 'informational load'. Besides for complexity caused by interactions we do not need so many actors to make it happen. Solving a twobody problem is an easy job; if you only add a third it becomes a trouble.

Fisher model is a phenotypic one: don't matter how genotypes are. But there is the tacit assumption, that you can perfectly map phenotypes to genotypes and that the genotype is able to smoothly model any phenotype that the environment could request, through universally pleiotropic effects. As Orr put it: "Because selection shapes adaptation from a supply of continuous, nearly fluid variation, mutation on its own provides little or no phenotypic form" (Orr 1998). Hence "There is little reason, after all, to ask non-trivial questions about the genes that underlie adaptation if one assumes that there are thousands of them, each with small and interchangeable effects on the phenotype" (Orr 2005, pag 120). In the end, biology doesn't matter. As Punnett noted, Fisher's biology is "too much of the order of problem that deals with weightless elephants upon frictionless surfaces...." ( quoted by Rao et al, 2011, p 275).

Let's pause for just a moment to reflect on some of the concepts Environment is obviously a somewhat coarse concept. As Herbert Simon says "the term 
environment is ambiguous. We are not interested in describing some physically objective world in its totality, but only those aspects of the totality that have relevance as the 'life space' of the organism considered. Hence what we call environment will depend upon the 'needs', 'drives', or 'goals' of the organism, and on its perceptual apparatus' (Simon, Herbert A.1956, p.130) We wonder how many and what the environmental features might be. Neutrinos, for instance, are part of the environment of all living beings, but no living being can fit them. Magnetic fields are also part of the environment of all living beings, but only a few fit them. Boiling water is part of the environment of the lobster, but no lobster can cope with it, unless you think it has developed the propensity to be cooked. As Lewontin put it "Organisms do not experience environments. They create them. They construct their own environments out of the bits and pieces of the physical and biological world and they do so by their own activities [ namely through ontogeny]." (Lewontin 1993, p 42; see also Laland et al. 1999). What really matters is not the environment, but the environmental features that living beings are designed to fit. We could perhaps say niches, were it not that the concept of niche is stained by the same sin of essentialism that affects many other concepts of population genetics, say species, individual, fitness. Despite the Darwinian religion, widespread among evolutionists, scholars often forget what is Darwin's main teaching: essentialism is mistaken, pace Kauffman (Dennett, 2009; Sober1980; Hull, 1965). It is precisely because of essentialism that the niche concept has by some years been challenged by the neutral theory (Hubbell, 2001) The concept of niche - I mean realized niches, different from fundamental niches, that are only theoretical entities (Hutchinson 1991) -- is based on the idea that the environment is split into different patches suitable for different species, as if they would be arranged in the environment (in the multidimensional space of environmental features) as a jigsaw puzzle. Ecological niches are not out there waiting for organisms to evolve to fill them. Niches are fuzzy and often overlap and fluctuate (Broennimann et al 2012; Hurlbert 1978). "Vagueness is the rebellion of truth against intellect", as you can read in the Newly Discovered Maxims of La Rochefoucauld (Russell 1972). It would be better to speak of organismic Umwelt, extending the concept of perceptual Umwelt introduced by Jakob von Uexküll ( 1992). In the end, everyone pulls a living as he can, according to the environmental affordances (Gibson, 1977) suitable for the toolbox (a box of coadapted anatomical, physiological, perceptual as well behavioral tools) of which he is equipped. The matching of the toolbox with the environment shapes the organismic Umwelt. But the toolbox has to be ontogenetically tuned at the environmental affordances through experiences, so one and the same toolbox can produce different Umwelten (figure 2). 


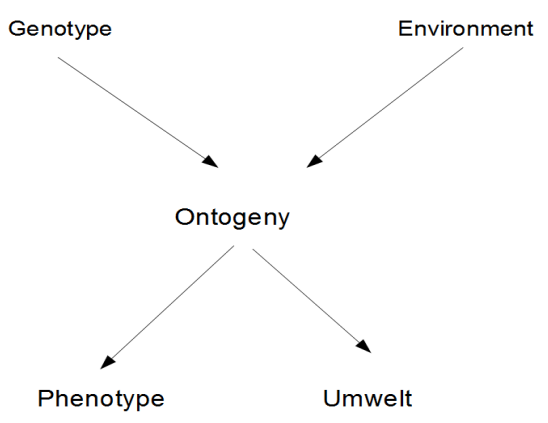

Figure 2

In an environment mainly homogeneous and stable we can expect that quite all individuals in a population share the same Umwelt. But in a heterogeneous environment differences in genetic endowment and ontogeny can shape different Umwelten for different individuals in one and the same population. This doesn't mean that the objective environment doesn't matters. It matters a lot. But what is it really, once you have subtracted the Umwelt? Well, it can be a source of unlucky pitfalls, as it continues to be a flame for moths or a window pane for flies, as well as a source of serendipitous discoveries for new happy Umwelten, as were, say, colors for primates.

Let's come back to the multidimensional sphere. Some observations are appropriate about it. A population can't be obviously represented by a point A on a surface of the sphere, unless you leave aside standing variation. To be sure, in Fisher's view, polymorphism may be only exceptional and can safely be ignored. "The phenomenon is sufficiently uncommon to suggest that it must always owe its origin in some rather special circumstances" (p. 166). In fact this is just what all eugenicists think. But polymorphisms are actually widespread and count a lot for evolution (Orr 2005), Hence a population could rather be represented as a cloud of points scattered in a shell of average distance $\mathrm{d} / 2$ from the point $\mathrm{O}$. Be aware, this one is only a first cloud that we come across in the path toward optimality, not so serious, to tell the truth, as we might perhaps assume the point A as the average, at least for the distance, of all points of the cloud, assuming the fancifully way biologists have invented to measure individual fitness (but see, for instance, Ariew and Lewontin 2004 or Dawkins,1982 chap 10). Unfortunately, other more serious clouds are in sight around the point $\mathrm{O}$.

Fisher's model claims to unify at the point $\mathrm{O}$ both environmental features (Futuyma and Moremo 1988) and biological optimal traits, that are assumed to match perfectly with each other. Hence we can say there are two conceptually distinct points $\mathrm{O}$ : environmental $\mathrm{O}$, namely a point (or rather a volume) in the n-dimensional hyperspace (Hutchinson 1991) and organismic O, that, according to 
Fisher, should coincide. Well, as Duhem noted (Duhem 2004), the same set of data can be fitted by different scientific theories, similarly as the same set of environmental features can be fitted by different set of traits. There are, to be true, many points $\mathrm{O}$ in the space of organismic traits that can fit the same set of environmental features, as we can see in converging evolution. As Holland has put it, "distinct coadapted sets of alleles can exploit the same environmental niche" (Holland 1992 p.11). Well, I wonder how you can calculate an average value between different sets of traits or alleles.

But the point $\mathrm{O}$ also refers to the set of environmental features which are fitted by the right arrangement of traits. There are as well many different sets of features in one and the same environment that could operate as different organismic Umwelten for slightly different organisms within the same population. We are faced again with a cloud of points (or, perhaps, ypervolumes with different set of dimensions) between which it is not possible to determine an average value. It is not $\mathrm{n}$ (the number of traits) that produces complexity, but how different environmental features interweave with different organismic traits. And complexity does not just slow down the walk towards optimization, but, as we'll see, makes impassable the roads leading to it.

The only remarkable thing in Fisher's model, which Fisher miss to note, but which will be further emphasized by Orr, is that the diameter of the sphere decreases as we approach the optimality, so that the steps towards optimality become increasingly smaller. Unfortunately, when they have become too small, Mother Nature, as Kimura noted (Kimura 1983), might probably miss to pick them, and they will be subjected to random drift. We'll come back to this later, when talking about NK model.

Meanwhile let's fantasize how the machine of adaptation in complex environment, which can host different Umwelten, could perhaps work.

Pick up two human beings, say Marilyn Monroe and John von Neumann. Let's suppose that Marilyn is a bit fitter than John; hence they are located in two distinct points in the cloud around the point A, the population's average fitness. But they have probably two slightly different Umwelten, depending on genetic endowment and ontogenetic adaptation; so their points $\mathrm{O}$ (traits optimality) don't coincide, although are probably located near one another in two subspaces of the space of traits. (Holt 1985) But you can not calculate the average value of the different points O, because no biologist has ever found a way to assign a measure to an arrangement of traits. An arrangement of traits can be a point in the multidimensional phenotype space ( Doebeli and Ruxton 2000).

Assuming assortative mating, as Fisher (1922) would have suggested, we may expect that Marilyn will spread and in a few generations there will be more Marilyns and not so many Johns . As 
Marilyn's Umwelt is becoming too much crowded and nearly filled up, the success of Marilyns will start to decrease (Gromko 1977, Bolnick 2002). Sic erunt novissimi primi, et primi novissimi. Anyway, as organisms, different from what Fisher thought, are not microscopes, some Marilyns could change their Umwelt, through ontogenetic adaptation and end up doing the scullery maids, that is not a bad choice ( Hammerschlag-Peyer et al. 2011). Later genetic assimilation (Waddington 1942 ; Schmalhausen 1949) will perhaps transfer ontogenetic adaptation in genetic one (Ackerly 2006). If the genes responsible for locale adaptation are the same as the genes underlying reproductive isolation, we can even have sympatric speciation and a new species could arise, say Marylina famula. Meanwhile Johns, as their Umwelt is not so crowded, maintain their fitness and slowly duplicate, so in a few generations we'll probably find Johns, not only at Princeton, but perhaps at Harvard as well at Stanford or MIT. But if they increase too much, some will perhaps end up perhaps being stevedores, also going through ontogenetic adaptation. In the end, who can say, even Johns can branch in speciation. .

If you suspect that what we can fantasize about humans, who live in a very heterogeneous environment, is quite impossible for animals, I must say you're right, if you're thinking of Merluccius merluccius, who lives in a uniform environment, but you're dead wrong if you think, say, of Larus argentatus (Pierotti and Annett, 2001), or Darwin's finches. You can see the extensive literature around the individual specialization and individual-level niche (namely Umwelt) variation, starting, say, with Van Valen (1965), passing through West Eberhard (1989) and finishing with Bolnick (2003, 2004, 2006).

To be true, the only thing Fisher was really talking about is a multidimensional sphere and, perhaps, eugenics; certainly not biology. Nor we can find much biology in his fundamental theorem, or rather platitude (Price 1972). Natural selection, in Fisher view, will select those that it thinks are the best beans at time $t$, consuming the variance, namely the fuel for increasing of fitness. When there will be no longer variance, there will be nothing to choose and all will remain as before: no increasing of fitness at all. Anyway what is the best today, could perhaps be the worse tomorrow. In the end natural selection should work to decrease genetic polymorphism and produce excellent individuals doomed to die, meanwhile lowering the resources of the gene pool doomed to persist (Reed, 2003). You have to be very professional, namely idiot, if you think such a model can work. As Price (1972, p.140) noted: "Fisher's fundamental theorem of Natural Selection is mathematically correct but less important than he thought it to be". All in all not a great gain for biology, because if you add biology the theorem doesn't work. Besides The genetical theory of natural selection, as you surely know (if only you have read it), is not a book about natural selection but about eugenics and racism. What Fisher was worried about is the possible decline of our 
civilization, that, in his mind, might be caused by the sterility of the upper class and the promotion of individuals of lower classes, lacking the genetic endowment needed to govern. Each one has its own worries. Anyway racism, parochialism, eugenics and the like are not, in the end, so bad . They are natural instincts that have done, in the past, their function, perhaps no longer useful today. What is really serious is to mistake eugenics for science.

This can be enough for Fisher's eugenics and his bad caricature of Darwinian adaptation (Orr 1998).

But what about Wright's model?

Obviously the point clouds I'm talking about have something to do with the ruggedness of the fitness landscape that Wright introduced in 1932 (Wright 1932), about which there has been a lot of chatter since then. Wright, to be true, had guessed that adaptation is not so simple as Fisher thought, and looked at the problem from the opposite point of view, focusing on genotype instead of phenotype. Not even he realized that the major problem around adaptation is in the relations between them mediated by ontogeny. Anyway his model may be easily summarize.

Let's assume a genome with $\mathrm{n}$ loci, each of them with a variable number of alleles. If there was an optimal allele for each gene, there would be no difficulty at all. One by one, all optimal alleles might go to fixation, and optimality would be achieved (if only we can leave aside random drift). Wright knew that it is not so, because the selective value of a genome "does not depends on strict or even approximate additivity of the effects of the component genes. There may be gene interactions (epistasis) of various sorts" (Wright 1988 p.115). Hence the problem for evolution is to find up the best combination of alleles, among zillions of different ones. Well, we can imagine that all possible genomes are distributed in such a way that each one is surrounded by those from which it differs only for a single allele.

For a genome of, say, five genes, each with two possible different alleles, there would be obviously $2^{5}$ different combinations, the field of possible gene combinations, which we can arrange so as any genome is near to five others that differ for a single allele and can be reached by a single step. Wright showed as 32 genomes can be distributed at the vertexes of a multidimensional polyhedron, each one surrounded by the five that differ by only one allele (figure 2) 


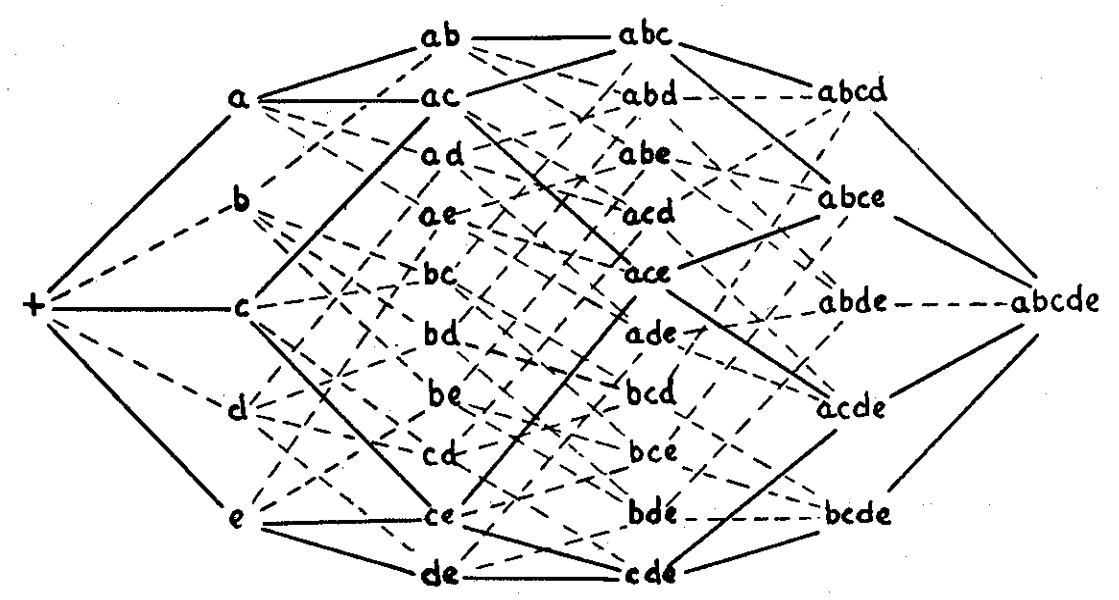

Figure 2 - The combination of 5 paired allelomorphs

Obviously if genes are some thousands and the alleles are more than two, the multidimensional polyhedron would be a bit trickier. After confusing reader's mind and probably even his own, Wright plays his sleight of hand. He squashes, I don't now how, his multidimensional pumpkin on a flat surface, adds a third dimension as a measure of fitness and invents the adaptive landscape with peaks and valleys. Surely the z-axis is there to measure fitness, but it is not clear what the $\mathrm{x}$ and y axes might measure. Notwithstanding this great confusion, the adapted landscape has dominated evolutionary biology for eighty years. I wonder how such an idiotic model could have been successful among scholars.

Wright's problem was, once again, optimization. Let's see why. One genome, in our zilliondimensional pumpkin, might be surrounded by genomes less fit. When we crush the pumpkin and add a third dimension for fitness, it stays on a peak surrounded by valleys. Unfortunately this might perhaps be only a local optimum. How can the genome jump on the highest peak, avoiding the temporary decrease in fitness incurred when crossing the surrounding valleys? To solve this problem Wright invented the well-known shifting balance, as it were a great discovery: to put it simply, some casual drift, not much deleterious, can drive a subpopulation across valleys, then the two subpopulations will compete and the fitter one will win (Coyne et al. 2000) One can wonder why on earth a population should stay all on the same peak. You must really suffer from eugenic syndrome if you think so.

What Wright miss to take into account is the heterogeneity of the environment within which it is possible to cut out different Umwelten through ontogeny. In practice he takes into account only the cloud of points $\mathrm{A}$, taking for granted the existence of a single point $\mathrm{O}$

We must add that a pumpkin squashed on a flat surface is not the same thing as a pumpkin with all 
its zillions of dimensions on. Hence Wright was worried about a problem that doesn't exist, because there could be in this zilliondimensional pumpkin "tunnels, bridges and even more convoluted topological features" (Holland, 1992, p 67). The real difficulty for higher organisms living in complex Umwelten, carved out in fluctuating environments, with genes interacting with each other, is to see if there is really something as a highest peak, namely if it can make sense to speak of optimizing the individual as a whole.

To be sure, the most serious problem about adaptation is the mapping of genotype to phenotype, with all surrounding problems of ontogeny, namely epigenesis, canalization, redundancy....; almost nothing is clear on this issue, apart from the case of deleterious genes. Hence, focusing on phenotypes, as Fisher did, or on genotypes, as Wright did, means not even entering the problem. In technical parlance this is properly named brain masturbation, a very popular sport among population geneticists.

To be sure for all of those who are suffering from eugenic syndrome, genetic polymorphisms is a serious problem. In fact if there is an optimal allele, one may ask why it has not gone to fixation. Heterosis and mutation-selection-balance can be the only explanations, but neither is really satisfactory. As Lewontin et al. (1978) demonstrated, heterosis doesn't work because " Even when all heterozygotes are more fit than all homozygotes, the proportion of fitness arrays that will lead to a stable, feasible equilibrium of more than 6 or 7 alleles is vanishingly small. And the mutationselection-balance hypothesis requires mutation rates much higher than they are" (p 149). Anyway, if you think Mother Nature is striving for optimality, you must know that optimization is not an easy job to be accomplished. Let's assume that a population is walking toward the highest peak. Obviously you do not have to ask if lions or mice or human beings are climbing or are instead on the highest peak, because it's not so clear what climbing could mean and what a peak is. Let's say they are climbing. There could be several different obstacles to the reaching of the peak, perhaps more serious than Wright thought. We can summarize them here, for correlated and uncorrelated spaces, based on Kauffman's NK model. (Kauffman, 1996). Real life is obviously a bit trickier than NK model. This can, however, provide some hints. N, as you know, is the number of entities, say genes; $\mathrm{K}$ is the number of interactions, say epistasis.

As Kauffman put it " $\mathrm{K}=0$ corresponds to the additive genetic model and yields a single-peaked and smooth correlated fitness landscape" (p 45). In such a space there is gradual adaptation and the only obstacle to the achievement of global optimality is natural selection, which is not up to the task: it is not watchful enough to select slightly advantageous mutations nor strong enough to eliminate slightly harmful ones. The first deficiency, as we have seen, was stressed by Kimura in his criticism toward Fisher's micromutational model, and the second one is its reciprocal. Both are 
clearly put down by Kauffman: "Random drift prevents the attainment and maintaining of the peak and the population wanders within a suboptimal shell around it. Thus from both the global optimum and a random initial starting genotype, the system falls or climbs to the same intermediate level of fitness. This represents the neutral shell within which the population thereafter wanders.” (p 98). This is, in Kauffman, view a first complexity catastrophe. To be sure there is neither complexity, as we have seen, nor catastrophe. Surely Kauffman is very fond of a dramatic vision of the world and want to find catastrophes everywhere. This is by no means a catastrophe, this is simply the load of information, which arises as its amount increases. Information can be very useful, but is costly to be acquired and burdensome to be managed. When you reach what Schuster called the error threshold (Schuster, 2013) it is not longer worthwhile to gather more information, because its cost outweighs the benefit that it is able to supply.

We attain akin results if we suppose that a population of suboptimal entities is walking toward optimality, randomly exploring possible choices by long jumps; it doesn't matter how correlated the space could be, because long jumps disrupt correlation. Without much mathematical garbage or computer simulations, any yahoo can easily guess that if the entities are of a low rank order, many better alternatives are probably available. As the rank order increases, it becomes increasingly difficult to find a better choice, because the possible better choices at each jump on average are halved. If you don't trust yahoo's guess, you can resort to the theory of records (Feller. 1971), which is a bit more prestigious, but this wouldn't add much to the guess of our yahoo. Meanwhile random deleterious mutations continue to worsen the exploring entities. The rate of improvement decreases at each step, while worsening remains constant, hence optimality will never be achieved and we are again with a cloud of points in a shell almost selectively neutral around optimality. Again, no catastrophe at all, only a gradual decrease in the benefit, until the marginal profit disappears.

Real complexity arises when epistasis and conflicting constraints intervene. Let see how Kauffman clearly put it: "if genes $i$ and $j$ influence each other, the optimal choice of allele for $i$ in the context of all possible choices of alleles at $j$ will typically not be identical to the optimal allele at $\mathrm{j}$ for all possible alleles at $\mathrm{i}$. These conflicting constraints mean that the best mutual choices of alleles tend to be poorer overall". (p.52) As the number of genes $(\mathrm{N})$ and epistasis $(\mathrm{K})$ increases, the number of conflicting constraints increases as well, hence "optimization can attain only ever poorer compromises. No matter how strong selection may be, adaptive processes cannot climb higher peaks than afforded by the fitness landscape" (p. 53-54)

All of these limits on the optimization process take us back to what H. Simon $(1972,1991)$ called bounded rationality, whose boundaries lie precisely in "knowledge limits, computational 
limits, incomparability of components goals" (Gigerenzer, 2004, p 91), namely informational load, computational load and conflicting constraints.

We can wonder how Mother Nature can cope with these limits. Well, one might reasonably ask why not fix epistasis in such a way that no conflict arise. Epistatic interactions should neither be distributed randomly among loci nor in the spirit of a democratic egalitarianism, as Kauffman assumes, namely each locus one interaction or how many you like, up to N-1. Human technology usually prevents conflicts by resorting to modules, which must obviously be coordinated with each other, but do not affect each other. The theme of modularity was first hinted at by Needham (1933) and later taken up by Lewontin (1974) in his criticism of adaptationism. It was then extensively treated by Fodor (1983) about mind and has spread in evolutionary psychology. It has eventually been placed on the stage in the extended new synthesis under the sponsorship of Simon (Callebaut et al. 2005). We can add that behavioral ecologists, looking at optimization of single traits, as, say, gait or fly or foraging, implicitly assume modularity; and they are surely right, if we leave aside the correctness of the single analyzes and the strange inclination to invent a gene for each behavior, resorting to what has been called the phenotypic gambit (Grafen,1984). If there are some stable environmental features that are worth to be fitted, evolution will probably do the work. They are instead dead wrong while claiming to scale up from single traits to the individual as a whole, which should be designed as inclusive fitness maximizing agent: I wonder what on earth this could mean.

If adaptation focuses on modules, there are no longer cognitive or computational limits, as it is well defined what each trait has to fit on its own, nor incompatibility of component goals, because each trait has its own goal. But optimizing modules, designed to fit stable or predictably changing environmental features, doesn't mean optimizing individuals altogether, because in heterogeneous environments there is a lot of unforeseen which individuals must face. All of these difficulties are discharged to ontogenetic adaptation, which is in charge of tuning the tool-box to the environment in order to shape the appropriate Umwelt. There would perhaps be a single way to be optimal, but for suboptimal organisms there may probably be several ways to get on with life (Kerr et al, 2002).

All this means that optimality is not simply difficult to be achieved because of the boundaries of rationality, but just does not exist, because there are many of good ways to stay alive and eventually reproduce.

That's why individuals are not selected. In fact I guess you don't really believe in the absurdity of individual selection. As Wallace pointed out to Darwin, offspring are not a subset of parents (Price1995). Or, as Ariew and Lewontin (2004) put it, "we must not confuse "the rate of 
reproduction by a genotype with the rate of reproduction of a genotype" (p. 352). Since Darwin, evolutionary biologists have mistaken natural selection for artificial selection. They are different and oppose to each other. Breeders chase individuals, Mother Nature chases environment. Breeders shape in their mind the model of individuals they aim for and, when their goal is achieved, strive to ensure that offspring are like their parents, often providing the right environment too: a cage, for instance, can be the right environment for hens. Mother Nature has no model in her mind, otherwise she would not have invented the randomness of recombination. She only throws tosses and sees, while chasing environment, and any toss is a bet. Population geneticists usually start from individuals, assuming asexual reproduction, and then add sex as a freak accident. This is really a wrong way to look at life, as sex is the unity of the gene pool; this means that individuals, as Williams suggested (1992), are not so important (fig.3)

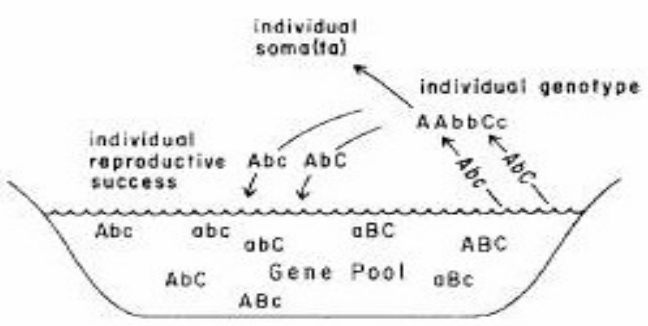

Figure 3

Relationship among the concepts of gene, genotype, gene pool, and individual soma. Only the soma represents a concrete object. The other entities exists as information(the codical domain). The differential success of individual genotypes in contributing genes to a common gene pool, as shown here, is the only legitimate meaning for the term individual selection (Williams, GC - Natural selection p.87)

Individuals are random tosses drawn from selected information (modules or building blocks) provided by the gene pool. Why random? Well, probably because Mother Nature doesn't know for sure what is a good model (Holland 92); she only has a clue. When almost sure, as it often happens, say, with acari or fungi, she doesn't behave randomly, but just repeats the previous toss that has succeeded. Hence fitness is primarily a property of the gene pool, and only secondarily a property of individuals, which are fit only on average. Modules, not individuals, are the entities to be optimized. As Sober put it "Charlie the Tuna is not a particularly interesting object of study, but tuna dorsal fins are" (Sober 2006, p. 26). Each individual obtains an almost optimal toolbox, namely modules, designed to fit environmental features which are stable or can change in predictable ways. Nevertheless, a lot of unforeseen occurs in the environment which complex organisms are faced with, and surely no genetic endowment is competent, on its own, to deal with unforeseen. Only ontogeny could perhaps do the work through individual adaptation.

If population geneticists are so smart to invent stories, adding up prestigious mathematical 
garbage, why no one has guessed that optimization is not probably the right tool to investigate evolution in complex organisms and that satisficing (Simon1956) could be enough ? Why are population geneticists so attached to optimization, as well as neoclassical economists are attached to rational choice? Probably because, if you give up optimization and rational choice, you must give up much of mathematical garbage too, as well as the hope of making biology and economics hard sciences. As Dugatkin has written, “ biologists who focused on behavior suffered from what one might call "physics envy," in that they saw equations not only as tools that promote generation and hypothesis testing, but also as objects that garner respect from other scientists." (Dugatkin 2007). Foolish hope indeed: population genetics and economics, as well as astrology, are rather poor in prediction, the mark of hard sciences.

That can be enough for the eugenicist thinking of Fisher, Wright and their followers, Let's turn to Dobzhansky and the balance school. For Dobzhansky polymorphisms were not a serious problem. Genetic polymorphism, in his view, was the richness of a population. A lot of work was made by scholars connected to his school, starting from Levene (1953), about selected polymorphism "when more than one ecological niche is available". As Lerner (1954) noted "heterozygosity has a dual function in the life of Mendelian populations. On the one hand, it provides a mechanism for maintaining genetic reserves and potential plasticity, and on the other, it permits a large proportion of individuals to exhibit combinations of phenotypic properties near the optimum . Underlying both processes is the superior buffering ability of heterozygotes as compared with homozygotes.” (p. 108)

We may not review the overwhelming literature about polymorphisms in heterogeneous environments. What we have to underpin is that all these studies, although facing real life and not a fake one invented by geneticists, usually share the same shortcomings:

1 They usually assume that individuals are selected, focusing on individual fitness, while neglecting the fitness of the gene pool. The main exception is Lerner.

2 They assume that heterogeneity is an ontological property of environments and not a relational one. This means that environment can only be affected by temporal or spatial heterogeneity. If we return to Fisher model, they only allow a few, usually two, environmental points $\mathrm{O}$ (instead of a single point), but not the construction of possible different Umwelten based on environmental affordances.

3 They are unaware of ontogeny. This means that a single genotype can shape a single phenotype, good, at best, for a predefined niche; no clouds of possible phenotypes (organismic points $\mathrm{O}$ ) for different Umwelten (environmental points $\mathrm{O}$ ) carved out from one and the same environment. 
Notwithstanding these shortcomings, Dobzhansky school still offers the best shelter against the foolish eugenic theories of both Fisher and Wright with their followers.

Ariew, A., \& Lewontin, R. C. (2004). The confusions of fitness. The British Journal for the Philosophy of Science, 55(2), 347-363.

Bolnick, D. I., Svanbäck, R., Fordyce, J. A., Yang, L. H., Davis, J. M., Hulsey, C. D., \& Forister, M. L. (2003). The ecology of individuals: incidence and implications of individual specialization. The American Naturalist, 161(1), 1-28.

Bolnick, D. I. (2004). Waiting for sympatric speciation. Evolution, 58(4), 895-899.

Bolnick, D. I. (2006). Multi-species outcomes in a common model of sympatric speciation. Journal of Theoretical Biology, 241(4), 734-744.

Broennimann, O., Fitzpatrick, M. C., Pearman, P. B., Petitpierre, B., Pellissier, L., Yoccoz, N. G., ... \& Graham, C. H. (2012). Measuring ecological niche overlap from occurrence and spatial environmental data. Global ecology and biogeography, 21(4), 481-497.

Callebaut, W. G., \& Rasskin-Gutman, D. (Eds.). (2005). Modularity - understanding the development and evolution of natural complex systems. The MIT Press.

Coyne, J. A., Barton, N. H., \& Turelli, M. (2000). Is Wright's shifting balance process important in evolution?. Evolution, 54(1), 306-317.

Dawkins, R. (1982). The extended phenotype (Vol. 8). Oxford: Oxford University Press. .

Dennett, D. C. (2011). Homunculi rule: Reflections on Darwinian populations and natural selection by Peter Godfrey Smith. Biology \& Philosophy, 26(4), 475-488.

Dobzhansky, T., \& Levene, H. (1955). Genetics of natural populations. XXIV. Developmental homeostasis in natural populations of Drosophila pseudoobscura. Genetics, 40(6), 797.

Doebeli, M., \& Dieckmann, U. (2000). Evolutionary branching and sympatric speciation caused by different types of ecological interactions. The american naturalist, 156(S4), S77-S101.

Dugatkin, L. A. (2007). Inclusive fitness theory from Darwin to Hamilton. Genetics, 176(3), 13751380.

Duhem, P. (2003). Sauver les apparences: Essai sur la notion de théorie physique de Platon à Galilée. Vrin.

Fisher, R. A. (1930). The genetical theory of natural selection. Oxford: Oxford University Press.

Fisher, R. A. (1923). XXI.-On the dominance ratio. Proceedings of the royal society of

Edinburgh, 42, 321-341.

Fodor, J. A. (1983). The modularity of mind Cambridge. MA: Bradford.

Futuyma, D. J., \& Moreno, G. (1988). The evolution of ecological specialization. Annual review of Ecology and Systematics, 19(1), 207-233.

Gibson, J. J. (1977). The theory of affordances. Hilldale, USA, 1(2).

Gigerenzer, G. (

Grafen, A. (1984). Natural selection, kin selection and group selection. Behavioural ecology: An evolutionary approach, 2, 62-84.

Gromko, M. H. (1977). What is frequency-dependent selection?. Evolution, 31(2), 438-442.

Hammerschlag-Peyer, C. M., Yeager, L. A., Araújo, M. S., \& Layman, C. A. (2011). A hypothesistesting framework for studies investigating ontogenetic niche shifts using stable isotope ratios. PloS one, 6(11), e27104.

Holland, J. H. (1992). Genetic algorithms. Scientific american, 267(1), 66-73.

Holland, J. H. (1992). Adaptation in natural and artificial systems: an introductory analysis with applications to biology, control, and artificial intelligence. MIT press.

Holt, R. D. (1985). Population dynamics in two-patch environments: some anomalous

consequences of an optimal habitat distribution. Theoretical population biology, 28(2), 181-208.

Hubbell, S. P. (2001). The unified neutral theory of biodiversity and biogeography (MPB-32) (Vol. 
32). Princeton University Press.

Hull, D. L. (1965). The effect of essentialism on taxonomy--two thousand years of stasis (I). The British Journal for the Philosophy of Science, 15(60), 314-326.

Hurlbert, S. H. (1978). The measurement of niche overlap and some relatives. Ecology, 59(1), 6777.

Hutchinson, G. E. (1992). Population studies: animal ecology and demography. Bulletin of Mathematical Biology, 54(4), 695-695.

Kauffman, S. A. (1993). The origins of order: Self-organization and selection in evolution. Oxford University Press, USA.

Kerr, B., Riley, M. A., Feldman, M. W., \& Bohannan, B. J. (2002). Local dispersal promotes biodiversity in a real-life game of rock-paper-scissors. Nature, 418(6894), 171-174.

Kimura, M. (1983). Rare variant alleles in the light of the neutral theory. Molecular Biology and Evolution, 1(1), 84-93.

Laland, K. N., Odling-Smee, F. J., \& Feldman, M. W. (1999). Evolutionary consequences of niche construction and their implications for ecology. Proceedings of the National Academy of

Sciences, 96(18), 10242-10247.

Levene, H. (1953). Genetic equilibrium when more than one ecological niche is available. The American Naturalist, 87(836), 331-333.

Lerner, I. M. (1954). Genetic homeostasis. Genetic homeostasis.

Lewontin, R. C. (1993). The Doctrine of DNA Biology as Ideology.

Lewontin, R. C. (1974). The genetic basis of evolutionary change (Vol. 560). New York: Columbia University Press.

Lewontin, R. C., Ginzburg, L. R., \& Tuljapurkar, S. D. (1978). Heterosis as an explanation for large amounts of genic polymorphism. Genetics, 88(1), 149-169.

Mayr, E. (1954). Change of genetic environment and evolution.

Mitchell, M. (2009). Complexity: A guided tour. Oxford University Press.

Needham, J. (1933). On the dissociability of the fundamental processes in ontogenesis. Biological Reviews, 8(2), 180-223.

Orr, H. A. (2000). Adaptation and the cost of complexity. Evolution, 54(1), 13-20.

Orr, H. A. (2005). The genetic theory of adaptation: a brief history. Nature Reviews Genetics, 6(2), 119-127.

Orr, H. A. (1998). The population genetics of adaptation: the distribution of factors fixed during adaptive evolution. Evolution, 52(4), 935-949.

Orr, H. A. (2005). The genetic theory of adaptation: a brief history. Nature Reviews Genetics, 6(2), 119-127.

Pierotti, R., \& Annett, C. (2001). The ecology of Western Gulls in habitats varying in degree of urban influence. In Avian ecology and conservation in an urbanizing world (pp. 307-329). Springer, Boston, MA.

Rao, V., \& Nanjundiah, V. (2011). JBS Haldane, Ernst Mayr and the beanbag genetics dispute. Journal of the History of Biology, 44(2), 233-281.

Reed, D. H., \& Frankham, R. (2003). Correlation between fitness and genetic

diversity. Conservation biology, 17(1), 230-237.

Schmalhausen, I. I. (1949). Factors of evolution: the theory of stabilizing selection.

Schuster, P. (2013). The mathematics of Darwinian systems. From strange simplicity to complex familiarity. A treatise on matter, information, life and thought. Appendix A, 4, 667-700.

Simon, H. A. (1956). Rational choice and the structure of the environment. Psychological review, 63(2), 129.

Simon, H. A. (1972). Theories of bounded rationality. Decision and organization, 1(1), 161-176. Simon, H. A. (1991). Bounded rationality and organizational learning. Organization science, 2(1), 125-134. 
Sober, E. (1980). Evolution, population thinking, and essentialism. Philosophy of Science, 47(3), 350-383.

Sober, E. (2006). The two faces of fitness. Conceptual issues in Evolutionary Biology, 25-38.

Van Valen, L. (1965). Morphological variation and width of ecological niche. The American

Naturalist, 99(908), 377-390.

Waddington, C. H. (1942). Canalization of development and the inheritance of acquired

characters. Nature, 150(3811), 563-565.

Wright, S. (1932). The roles of mutation, inbreeding, crossbreeding, and selection in evolution (Vol. 1, pp. 356-366). na.

Wright, S. (1988). Surfaces of selective value revisited. The American Naturalist, 131(1), 115-123. Von Uexküll, J. (1992). A stroll through the worlds of animals and men: A picture book of invisible worlds. Semiotica, 89(4), 319-391.

West-Eberhard, M. J. (1989). Phenotypic plasticity and the origins of diversity. Annual review of Ecology and Systematics, 20(1), 249-278.

Williams, G. C. (1992). Natural selection: domains, levels, and challenges. Oxford University Press. 